\title{
Gewinnspiel
}

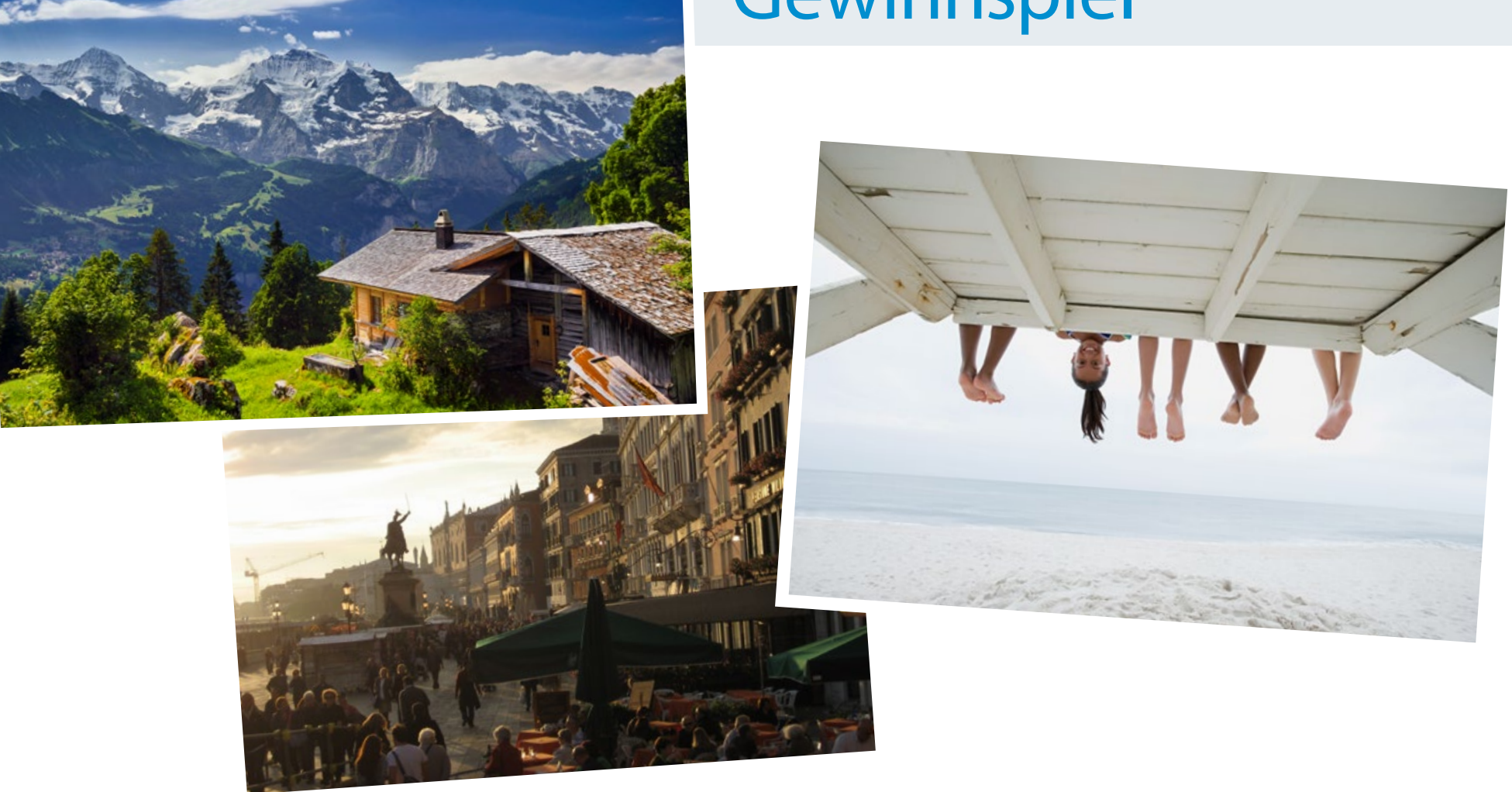

Mitmachen und gewinnen

\section{Gesucht: Ihr Lieblingsfoto 2015}

Vielleicht haben Sie von einer Ihrer letzten Reisen ein schönes Foto mit nach Hause gebracht oder auch in heimischen Gefilden ein tolles Bild geschossen. Teilen Sie dieses Foto mit uns und den Lesern von pädiatrie hautnah und schicken Sie uns Ihr schönstes Bild mit einer kurzen Erklärung zum Ort/Objekt zu. Das beste Foto veröffentlichen wir in der Dezember-Ausgabe. Unabhängig davon verlosen wir unter den Teilnehmern fünf wertvolle Preise.

\section{So nehmen Sie teil:}

Senden Sie uns Ihr Foto unter dem Betreff „Lieblingsfoto 2015“ per Mail an nadine.ziegler@springer.com. Achten Sie bitte auf eine möglichst gute Auflösung, die Dateigröße darf jedoch 8 Megabyte nicht übersteigen. Bitte geben Sie in Ihrer Mail auch Ihren Namen und Ihre Adresse an. Teilnahmeschluss ist der 15. November 2015

Mit der Einsendung des Fotos erklären Sie sich mit der Veröffentlichung einverstanden und räumen uns inhaltlich, räumlich und zeitlich das unbeschränkte Recht der Speicherung, Vervielfältigung, Verbreitung und Weitergabe in gedruckter sowie elektronischer Form ein. Das Copyright verbleibt bei Ihnen.

Eine Barauszahlung der Preise ist nicht möglich. Der Rechtsweg ist ausgeschlossen. Mitarbeiter des Verlags dürfen nicht teilnehmen.

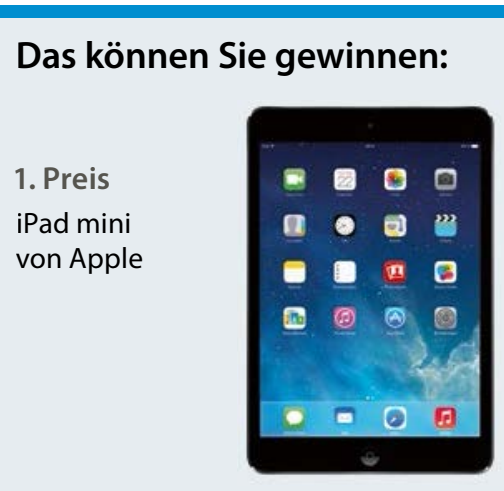

2.-5. Preis

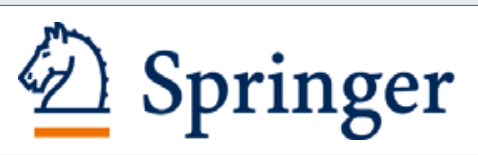

Je ein Gutschein über 100 Euro für ein Fachbuch von Springer 